\title{
JAIME E. RODRÍGUEZ O., EL LEGADO DE UN HISTORIADOR
}

\section{JAIME E. RODRÍGUEZ O., THE LEGACY OF A HISTORIAN}

\author{
Juan Luis Simal \\ Universidad Autónoma de Madrid
}

\begin{abstract}
Recensión de / Review of: Ivana Frasquet y Víctor Peralta (eds.), La revolución politica. Entre autonomias $e$ independencias en Hispanoamérica, Marcial Pons, Madrid, 2020, 302 páginas
\end{abstract}

Este volumen, coordinado por Ivana Frasquet (Universitat de València) y Víctor Peralta (Instituto de Historia, CSIC), está dedicado a Jaime E. Rodríguez O. y confirma el alcance del legado de su obra en varias generaciones de historiadores hispanoamericanos, españoles y anglosajones. Los participantes en el libro no solo fueron influidos en sus investigaciones por la lectura de la obra de Rodríguez, sino que muchos de ellos han sido sus discipulos o colaboradores. El respeto y la admiración hacia Rodríguez se aprecian en todos los capítulos.

El libro se divide en tres secciones: "ensayos" (textos que aportan reflexiones generales en diálogo con la obra de Rodríguez), "estudios" (capitulos basados en investigaciones originales centrados en un espacio hispanoamericano concreto y que emplean enfoques que beben de la obra de Rodríguez), y "testimonios" (aportaciones que tratan la contribución de Rodríguez a la profesión histórica y aspectos de su vida y personalidad).

El primero de los "ensayos" es un texto inédito del propio Jaime E. Rodríguez O., titulado "Revolución y colapso", que reproduce su conferencia inaugural en el Congreso de la Asociación de Historiadores Latinoamericanistas Europeos (AHILA) celebrado en Valencia en 2017. En él aparecen de forma condensada los principales ejes interpretativos formulados por Rodríguez para comprender históricamente el periodo de las revoluciones e independencias hispanoamericanas, construidos alrededor de una ambiciosa propuesta para repensar la dimensión politica revolucionaria contenida en la disolución de la Monarquía hispánica $\mathrm{y}$ en el nacimiento de los nuevos estados-nación hispanoamericanos, incluida España. De esta forma, huyendo de historiografias rendidas a relatos nacionales y teleológicos, la obra de Rodríguez puso en evidencia la intensidad y profundidad de la gran revolución política que surgió como respuesta al colapso de la Monarquía española tras la invasión napoleónica de 1808. Rodríguez introdujo dos grandes enfoques en el estudio de las independencias americanas: en primer lugar, rescató el peso de lo que denominó "autonomismo" en la solución política que se dio tanto en España como 
en América a la ausencia del monarca (lo hizo de forma contundente en su libro La independencia de la América española, publicado originalmente en castellano en 1996 y cuya versión inglesa se ha convertido en una referencia historiográfica internacional); en segundo lugar, hizo énfasis en la fortaleza y pervivencia del "hispanoamericanismo", es decir, de los lazos identitarios y politicos provenientes de una cultura común que dieron forma a ambos lados del Atlántico a una respuesta similar a la crisis politica de la Monarquía y que perduraron tras las independencias (aspecto ya presente en su primera monografia de 1975, fruto de su tesis doctoral, The Emergence of Spanish America. Vicente Rocafuerte and Spanish Americanism, de la que se publicó en 1980 una edición revisada en español).

Ciertamente, Rodríguez no fue el único que protagonizó esta renovación historiográfica. Él mismo siempre ha reconocido la influencia de su maestra en Estados Unidos, Nettie Lee Benson, pionera en el estudio de las instituciones de gobierno local y regional introducidas por la Constitución de Cádiz, en especial la diputación provincial, y de su impacto en el federalismo mexicano. Asimismo, Rodríguez alaba en su contribución a este libro la obra del historiador hispanofrancés François-Xavier Guerra. Ambos, desde posiciones académicas distintas, llegaron a conclusiones similares acerca de la profunda revolución política que tuvo lugar en el mundo hispánico, culminada por la Constitución de Cádiz. Este vigoroso diálogo historiográfico se enriqueció notablemente con la participación de muchos otros historiadores hispanoamericanos, como Virginia Guedea.

En efecto, la Constitución de Cádiz (acompañada por sus procesos electorales) ocupa un lugar fundamental en la obra de Rodríguez, y así lo demuestran los capítulos de este libro, que toman las múltiples aplicaciones del código doceañista como momentos axiales del periodo. Es conocida la tesis de Rodríguez de que el texto gaditano no fue un documento español sino una Constitución para el mundo hispánico, y que las aportaciones de los diputados americanos fueron fundamentales en varios aspectos, especialmente en lo tocante a la articulación territorial del nuevo Estado. Desde esta perspectiva, Rodríguez desarrolló en su obra la relación entre "autonomía" e "independencia", dos conceptos que aparecen en el título de este libro y a los cuales podría haberse añadido "representación".

Precisamente, muchos de los capítulos del volumen centran su análisis en las distintas formas de representación - ya sea territorial, política o social - surgidas en el contexto de la rearticulación constitucional de la Monarquía española. Así, Inés Quintero considera el ejercicio de la representación para el caso de Venezuela, en un análisis que se separa explícitamente de narraciones históricas nacionalistas para ubicar el juntismo venezolano en el contexto general de la disputa por la representación en el seno de las distintas instituciones surgidas a partir de 1808, en especial la Regencia y las Cortes de Cádiz. Brian Connaughton reflexiona sobre el papel que la religión y los eclesiásticos tuvieron en el surgimiento del gobierno 
representativo, intentando responder a la pregunta planteada por Rodríguez de "porqué los clérigos habian sido parteros de la independencia, pero perdieron el control de los destinos del México independiente". Por su parte Marta Irurozqui examina el papel jugado por los representantes de Charcas en el Congreso de Tucumán con el propósito de "eludir la trampa teleológica del Estado-nación o la inevitabilidad axiomática de la independencia”. En este capítulo se expone nitidamente la influencia de la tesis de Rodriguez acerca de que, en palabras de Irurozqui, "entre la posición fidelista a la Corona y la posición independentista de la misma estaba la postura autonomista: lealtad a la Monarquía española compatible con el autogobierno y la autoadministración locales". De aquí se desprende una postura rotunda: "pensar la nación no como causa, sino como una entre tantas alternativas posibles de construcción de una nueva comunidad política" en el contexto de la crisis de soberanía iniciada en 1808. Por su parte, Víctor Peralta examina en su capítulo la respuesta inicial que el virrey del Perú, Abascal, dio al desafio autonomista chileno. Su propósito es desentrañar el mito del "liderazgo contrarrevolucionario" de Abascal frente al autonomismo chileno, enmarcándolo en el contexto de aplicación del código constitucional de 1812. Abascal se propuso y, a pesar de sus errores, consiguió, mantener Chile bajo la autoridad de las Cortes de Cádiz como depositarias de la soberanía del rey. Solo la afortunada victoria de las fuerzas enviadas por Abascal en la batalla de Rancagua en octubre de 1814 llevó a la plena ruptura de los juntistas chilenos con la Monarquía española, que había retornado ya al absolutismo en mayo tras la anulación de la Constitución de Cádiz por parte de Fernando VII, noticia que no llegó a Chile hasta finales de ese año.

Dos capítulos se centran en el estudio de territorios que corresponden al actual Ecuador, donde Rodríguez nació en 1940. Ahmed Deidán de la Torre recompone el "rompecabezas" territorial e institucional del Reino de Quito antes, durante y después de la crisis de 1808 a través de un análisis enfocado en la dimensión local, mientras que Ana Luz Borrero estudia la participación política de los indígenas de Cuenca en la formación de los primeros ayuntamientos constitucionales, iluminando su papel como creadores activos de ciudadanía.

Otros dos capítulos analizan el otro país sobre el que, además de su Ecuador natal, Rodríguez centró sus investigaciones: México. Scott Eastman explora los "lazos transatlánticos raídos" entre la España peninsular y la Nueva España, identificando en la "esfera pública católica" un agente de transformación política revolucionaria que, además, canalizó la "creación de identidades nacionales" propias en ambos territorios que terminaron por desembocar en la ruptura de 1821. Este año fundamental para la historia política y constitucional de la Monarquía es el objeto del detallado análisis de Ivana Frasquet. En el contexto de la restauración de la Constitución en 1820, Frasquet esclarece las maniobras de los diputados novohispanos en las Cortes de 
Madrid para alterar las condiciones de representación y autogobierno llevando hasta el final su proyecto "autonomista", así como el viaje del último capitán general y jefe político de Nueva España, O'Donojú, que negoció con Iturbide los Tratados de Córdoba. Examinando el rechazo de los liberales peninsulares a esta "independencia pactada", Frasquet muestra que la Constitución no solo fue un proyecto panhispánico abierto a múltiples posibilidades de reordenación de la convivencia política, sino que también llegó a convertirse en un escollo para la búsqueda de soluciones pactadas a las reclamaciones de autonomía, confederación o independencia llegadas desde América, ya que tanto el Gobierno de Madrid como las Cortes afirmaron no poder aceptar unas propuestas que consideraban inconstitucionales.

En la última sección de "testimonios" dos capítulos exploran la actividad académica y profesional de Rodríguez. Mariana Terán examina el impacto historiográfico alcanzado por la interpretación de Rodríguez del liberalismo hispánico, evocando la renovación de la historia política de Zacatecas que propiciaron las visitas de Rodríguez a dicho Estado mexicano. Por su parte, Mirian Galante analiza el liderazgo de Rodríguez al frente de la revista Mexican Studies/Estudios Mexicanos, de la que fue editor general durante tres décadas y que se convirtió en uno de los principales vehículos de colaboración académica y acercamiento cultural entre Estados Unidos y México. El capítulo final es una sincera y afectuosa evocación biográfica de Rodríguez escrita por su compañera de vida, Linda Alexander Rodríguez. El libro se cierra con una completa bibliografia de la extensa obra de Rodríguez, que incluye 123 referencias publicadas entre 1974 y 2018.

En definitiva, este volumen es un oportuno reconocimiento de la obra de uno de los historiadores más influyentes de las últimas décadas, que atraerá a los estudiosos de la Era de la revolución en el mundo hispánico, así como a los interesados en la evolución de su historiografia.

Enviado el (Submission Date): 29/04/2021

Aceptado el (Acceptance Date): 5/05/2021 